The $B D J$ News section accepts items that include general news, latest research and diary events that interest our

readers. Press releases or articles may be edited, and should include a colour photograph if possible. Please direct your correspondence to the News Editor, Arveen Bajaj at the BDJ, The Macmillan Building, 4 Crinan Street, London N1 9XW or by email to bdj@bda.org

\section{New BDA President installed}

Manchester dentist Dr Josef L. Rich OBE was installed as the $120^{\text {th }}$ President of the British Dental Association (BDA) on 23 May. The installation ceremony took place at the start of the 2007 British Dental Conference and Exhibition in Harrogate. He will serve a 12-month term of office.

Born and educated in Manchester, Dr Rich studied at the University of Edinburgh. After graduating with his Bachelor of Dental Surgery in 1962, he served as an Associate at a prac tice in Manchester for three years. In 1966 he founded his own practice in Eccles, where he still cares for patients today.

As well as continuing to work in general practice, Dr Rich has served in different roles across the Manchester area. He has worked at Hope Hospital in Salford, as a lecturer at the University of Manchester, as the Dental Practice Adviser for Salford and Trafford and as Chairman of the Board of Management of the Manchester Dental Education Centre.

Dr Rich has represented practitioners as Chairman of the BDA's General Dental Services Committee and as a member of the BDA Council and the organisation's Representative Board. He has also served as Chairman of Salford Local Dental Committee. He is a member of dentistry's regulatory body, the General Dental Council, an office he has held since 1996. He is also a member of the Faculty of General Dental Practitioners (UK) and the Royal Society of Medicine.

\title{
Oral cancer management research recognised
}

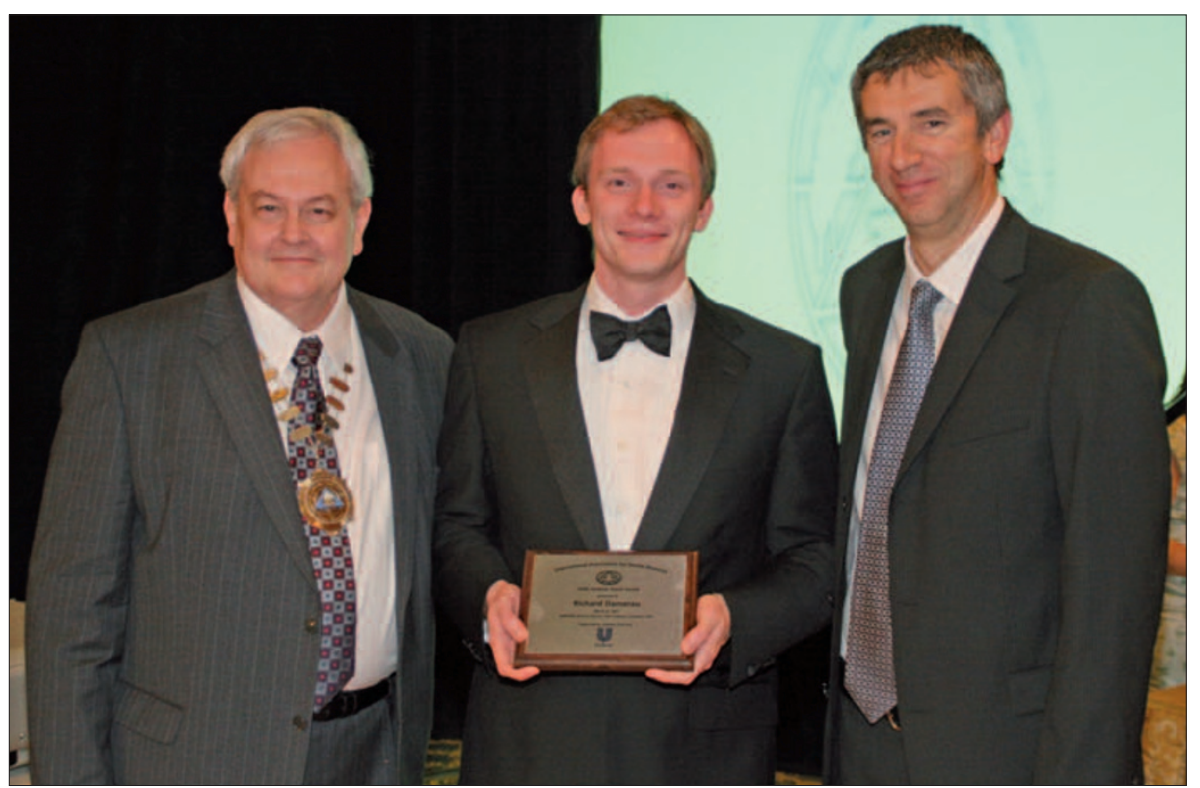

Richard Damerau from Barts and the London, Queen Mary's School of Medicine and Dentistry has won the International Association for Dental Research (IADR) Hatton Award (Junior category) for research in oral cancer. He looked at the role of insulin-like growth factor-1 (IGF-1), which reduces apoptosis (programmed cell death) in chemotherapy-treated oral neoplastic cells thereby possibly promoting chemotherapy resistance.

The research suggests that intracellular signalling pathway inhibitors may be able to reverse the effect of IGF-1. Therefore, a combination of conventional chemotherapy, such as cisplatin, and specific intracellular signalling inhibitors may become an adjunct to oral cancer management and may finally improve its prognosis.

The IADR/Unilever Hatton Awards competition is designed to provide an opportunity for the best junior investigators from all IADR Divisions to present their research at its annual general session. Recipients receive cash prizes and commemorative plaques in the junior and senior categories.

\section{Fluoride linked to gum disease}

Scientists from India have reported a link between dental fluorosis and periodontal disease. Inhabitants of the Davangere district of India were studied where natural water fluoride levels ranged from 1.5 to 3.0 parts-per-million (ppm) which is similar to fluoride levels allowed in US water supplies (up to $4 \mathrm{ppm}$ ). The sample consisted of 1,029 subjects between 15 and 74 years old. As the degree of dental fluorosis increased, periodontitis also increased. "The results suggest that there is a strong association of occurrence of periodontal disease in high-fluoride areas,' say authors Dr Vandana and Dr Reddy. The study appears in the Indian Journal of Dental Research (2007; 18: 67-71). 


\section{Toothbrush sharing}

Most Britons would be happy to lend their toothbrush to somebody else, according to a new UK-wide dental survey.

The National Smile Month Survey, commissioned by the British Dental Health Foundation in association with healthplan provider HSA, found that over $60 \%$ of people would be willing to let their partners, children, friends and even celebrities borrow their toothbrush.

The survey was commissioned to mark the 31st National Smile Month, which will runs from 13 May to 12 June 2007 with the theme of 'Two Minutes Twice a Day'. It found that men were far more protective of their brushes than women with almost half saying they would not lend their brush to anyone, as opposed to only a third of women.

Dr Nigel Carter, chief executive of the Foundation, commented, 'Sharing a toothbrush leaves people susceptible to oral and general health problems. Whilst this might be something relatively harmless, such as a common cold or cold sore, if the person you are sharing with is infected with hepatitis B or HIV these could also be passed on via the toothbrush with life threatening consequences.'

For more information visit www. dentalhealth.org.

\section{Molecule}

\section{that destroys and protects investigated}

An immune system component that is a primary cause of bone destruction and inflammation in autoimmune diseases such as rheumatoid arthritis actually protects bone in the oral cavity from infectious pathogens that play a major role in periodontal disease in humans, research at the University at Buffalo (UB), USA, has shown.

The component, IL-17, was recog-

\section{Fight tooth decay with chocolate, reveals study}

An extract of cocoa powder that occurs naturally in chocolates, teas, and other products might be an effective natural alternative to fluoride in toothpaste, according to research by doctoral candidate Arman Sadeghpour from Tulane University, New Orleans, USA.

His research revealed that the cocoa extract was even more effective than fluoride in fighting cavities. The extract, a white crystalline powder whose chemical makeup is similar to caffeine, helps harden tooth enamel, making users less susceptible to tooth decay. He claims the cocoa extract could offer the first major innovation to commercial toothpaste since manufacturers began adding fluoride to toothpaste.

Dr Sadeghpour adds that the extract has been proven effective in the animal model, but it will probably be another two to four years before the product is approved for human use and available for sale. He has already created a prototype of peppermint flavoured toothpaste with the cavity-fighting cocoa extract added, and his doctoral thesis research compares the extract side by side with fluoride on the enamel surface of human teeth.

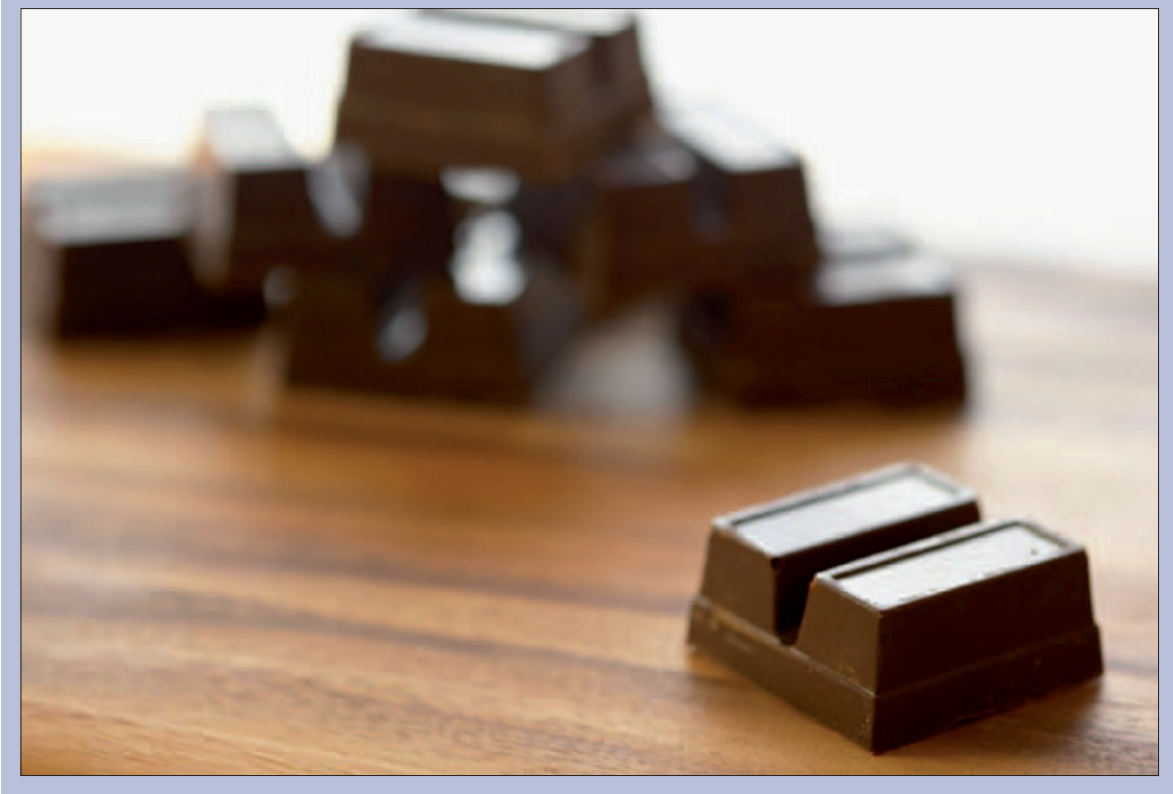

nised only in the past 18 months to be a primary cause of bone destruction and inflammation in autoimmune diseases. Therapies that target cytokine IL17 or its cellular receptor are currently being developed.

However, a UB molecular biologist has discovered that, in contrast to its action in rheumatoid arthritis (RA), IL-17 actually protects bone in the oral cavity from infectious pathogens such as Porphyromonas gingivalis, a bacterium that plays a major role in most periodontal disease in humans.

The research findings appear in the current issue of the journal Blood (2007; 109: 3794-3802).

Sarah L. Gaffen, Associate Professor of Oral Biology in the UB School of Dental Medicine and Associate Professor of Microbiology and Immunology in the
UB School of Medicine and Biomedical Sciences, and colleagues conducted the research in mice bred to have no receptors for IL-17.

Other researchers had shown previously, using rats and mice as animal models, that blocking the receptor for IL-17 could be an effective therapy for RA and possibly for other autoimmune diseases such as multiple sclerosis, colitis, psoriasis and lupus. The effects of an IL-17 deficiency in periodontal disease, however, were unknown.

Professor Gaffen said, 'Developing knowledge about the molecules that contribute to host defence versus pathology is very important for gaining a fundamental understanding of the immune system, but also because the consequences of therapies that target these cytokines need to be understood.' 


\section{Proposals for the new MFD RCSI outlined}

The Faculty of Dentistry of the Royal College of Surgeons in Ireland will replace the current three-part MFD Examination from September 2007 with a new two-part examination.

Candidates will be eligible for the award of the MFD Diploma provided they possess a primary dental qualification that is acceptable to the Councils of the Royal Colleges of Surgeons in Ireland and the UK, have completed a minimum of 24 months satisfactory whole time equivalent postgraduate experience, at least 12 months of which has been gained in clinical posts in vocational training, hospital or institutions either in Ireland or Overseas which have been approved for training by the Faculty of Dentistry of the Royal College of Surgeons in Ireland, have passed both sections of the MFD Diploma examination and complied with all the regulations.

To be eligible to sit Part 1 of the examination candidates are required to provide evidence of completion of a minimum of six months satisfactory full-time experience, or part-time equivalent, in any field of dentistry obtained after gaining their primary dental qualification.

The Part 1 examination will consist of two written papers, (a) multiple choice questions and (b) objective short answers. Part 1 will stand alone, candidates being awarded either a pass or fail and will be held at least twice a year. There is full reciprocity of recognition of a pass in Part 1 between the MFDRCSI and the MFDS RCSEdin and RCPSGlas. Details of other reciprocal qualifications will be posted on the College website when available.

Part 2 of the examination will be conducted at least twice a year in Ireland and once a year in approved overseas centres. The Part 2 examination will consist of an objective structured clinical examination with a minimum of 16 stations over a 90 minute period, and two 15 minute oral examinations assessing both applied basic sciences and clinical skills appropriate to 24 months postgraduate experience.

The Colleges have put in place transitional arrangements with respect to the current MFD/MFDS examinations and these are described below.

The final diet of Part A took place in April 2007, allowing candidates who failed Part A in April 2006 two further chances to pass. Candidates who proceed to sit the new Part $1 \mathrm{MFD}$, having previously failed the current Part A MFDS/ MFD, will be allowed the full five years in which to complete both parts of the new examination.

The final diet of Part B will be held in April 2009. This will allow candidates who hold Part A at least three chances to pass Part B. Candidates who have not passed Part B by April 2009 will thereafter be required to enter the new MFD examination at Part 1.

The final diet of Part C will be held in May 2007. Any holder of Parts A and $\mathrm{B}$ who has not yet passed Part $\mathrm{C}$ will be able to enter Part 2 of the new MFD examination when it is introduced in November 2007. Thus, holders of Parts A and B of the current MFDS/MFD examination will be exempt from the requirement to pass Part 1 of the new MFD examination. After passing Part B they will normally be allowed two years in which to pass Part 2 of the new MFD examination. The detailed regulations for the new MFD examination are available on the Faculty of Dentistry website - www. dentistry.rcsi.ie.

\section{New CPD programme launched}

Dentists can earn 12-hours a year of verifiable continuing professional development (CPD) by reading the $B D J$ 's sister publication $B D A$ News every month. The learning points and questions are based on areas of practice and business administration and complement the clinical CPD already available in the $B D J$.

The BDA News CPD programme was launched at British Dental Conference and Exhibition in Harrogate last month. Welcoming the initiative, the Chair of the BDA's Executive Board, Dr Susie Sanderson said, 'The BDA is very pleased to be introducing the CPD business skills in the June issue of $B D A$ News. We know that running a successful modern dental practice, in an increasingly commercial environment, requires business as well as clinical skills.'

\section{New overseas appointment}

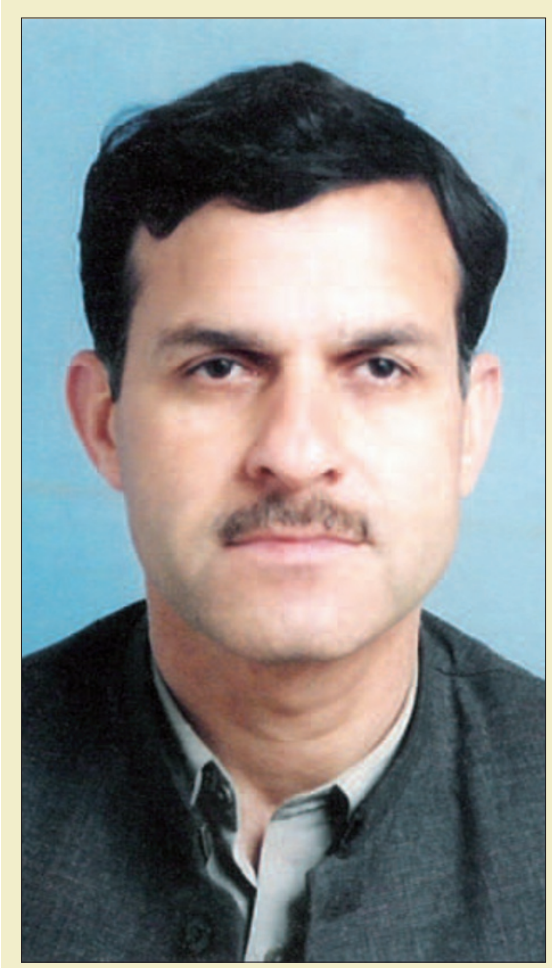

The Pakistan Medical Research Council (PMRC) has appointed Dr Fazli Ghani, Assistant Professor and Head, Department of Prosthodontics, Khyber College of Dentistry Peshawar, Pakistan, as Convener of its Expert Panel of Oral Health and as a member of the PMRC Technical Advisory Committee (TAC).

Dr Ghani's duties include reviewing, evaluating and recommending research proposals submitted to the organisation for funding, and reviewing the scientific literature submitted for publication in the Pakistan Journal of Medical Research.

\section{Death notice}

Professor Roderick Cawson, MD, FDS RCS, FDS RCPS, FRCPath, Emeritus Professor of Oral Medicine and Pathology at Guy's Dental Hospital (now King's College London Dental Institute), died on 25 April 2007.

He was 87 years old. He was internationally known by generations of undergraduate and postgraduate students as the author of many outstanding textbooks. A full obituary will follow. 


\section{DIARY}

June

14th Annual Congress of the

Turkish Dental Association

Date: 11-17 June 2007

Venue: Lütfi Kirdar Convention Center,

Istanbul, Turkey

www.tdbkongresi.com

21st Congress of International

Association of Paediatric Dentistry

Date: 13-17 June 2007

Venue: Hong Kong Convention and Exhibi-

tion Centre

Email: info@iapd2007.com

www.iapd2007.com

113th Meeting of the American

Dental Society of Europe

Date: 26-29 June 2007

Venue: Cameron House, Loch Lomond, Scotland

Tel: 01413310088

www.adse.co.uk

July

BDA Armed Forces Group AGM

Date: 5 July 2007

Venue: BDA Lecture Theatre, London

Tel: 01296656469

\section{September}

4th Annual Meeting of the

European Society of Estethic Dentistry

Date: Vienna, Austria

Venue: 21-23 September 2007

Email: iris.bobal@media.co.at

www.escdonline.eu

148th American Dental

Association Annual Session and

Marketplace Exhibition

Date: 27-30 September 2007

Venue: The Moscone Center,

San Francisco, USA

www.ada.org

\section{October}

Annual meeting of the Society of Craniofacial Genetics \& American Society of Human Genetics Meeting Date: 23 October 2007

Venue: Convention Center, San Diego, California, USA

www.craniofacialgenetics.org

FDI Annual World Dental Congress

Date: 24-27 October 2007

Venue: Dubai, UAE

Email: congress@fdiworldental.org

www.fdiworldental.org

\section{Tongue cancer risk uncovered}

Researchers have shown that an association exists between long-standing periodontitis and the risk of tongue cancer. The study by researchers at the University at Buffalo (UB) and Roswell Park Cancer Institute, USA, found that the risk of tongue cancer due to chronic gum disease increased five-fold with every millimeter of alveolar bone loss. The association existed even in the absence of a history of smoking.

The study compared panoramic dental radiographs of 51 white males newly diagnosed with tongue cancer with records of 54 white males without cancer. All patients were seen in the Department of Dentistry and Maxillofacial Prosthetics at Roswell Park Cancer Institute between June 1999 and November 2005. People less than 21 years of age, those with no teeth, and those with a history of any type of cancer, cancer therapy, oral pre-cancerous lesions, immunodeficiency or autoimmune disorders were excluded from the study.

Measurements of alveolar bone loss in all patients were made by the same periodontist, who did not know the cancer status of study participants. After eliminating from the analysis the potential effects of age, smoking status and number of existing teeth, patients with chronic gum disease were 5.2 times more likely to have tongue cancer with every millimeter of bone loss than those without gum disease. Other conditions involving the teeth such as decay, filings, crowns and root canals, had no significant effect on the incidence of tongue cancer, results showed.

Mine Tezal, Assistant Professor in the Department of Periodontics and Endodontics, UB School of Dental Medicine and research scientist at Roswell Park Cancer Institute explained, 'If this association is confirmed in larger studies with a broader population and in other oral cancer sites, it will have a significant impact on our understanding of the causes and origin of oral cancer, as well as its prevention and control.' Results of the study appeared in the Archives of Otolaryngology - Head and Neck Surgery (2007; 133: 450-454)

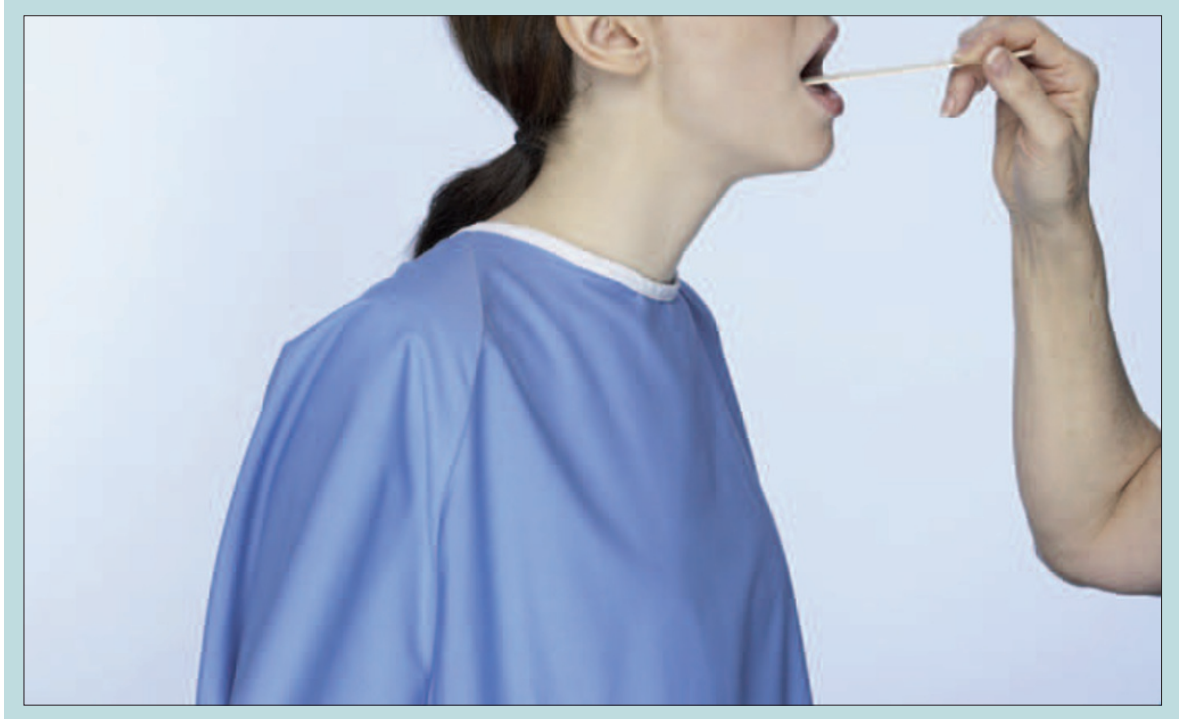

\section{Oral health meeting held in Rwanda}

Two years after the first ever oral health meeting in Rwanda initiated by the FDI World Dental Federation (FDI) and the World Health Organisation's (WHO) African Regional Organisation (AFRO), a follow-up workshop jointly organised by the Rwanda Dental Association (ARCDS) was held in the country's capital Kigali recently.

The meeting was dedicated to sup- port the process of developing the first oral health policy for Rwanda. Professor Charlotte Ndiaye, WHO AFRO's Regional Advisor for Oral Health commented, 'Oral health is important for overall wellbeing and general development. It is our responsibility to address it with appropriate policies and functioning essential services.' A plan of action will be implemented from 2007 to 2015 . 


\section{Straightening teeth naturally}

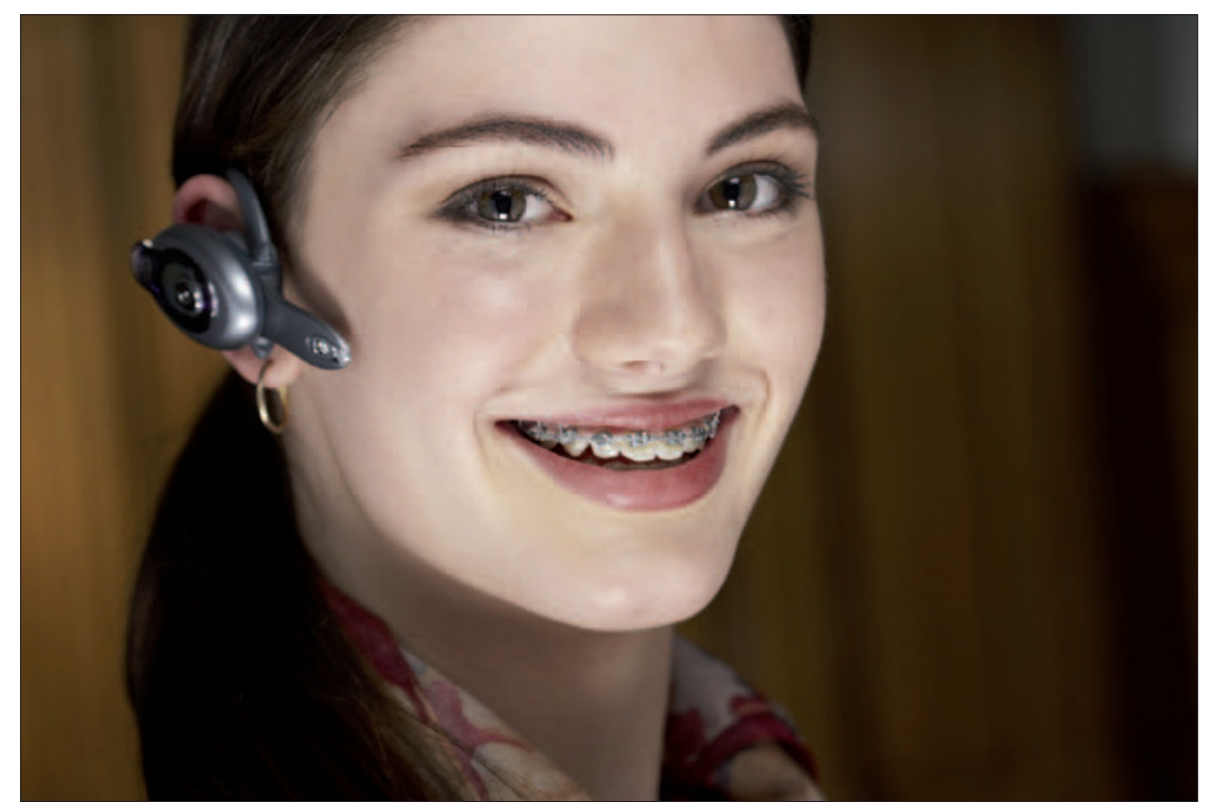

Research on identical twins suggests that traditional methods of straightening teeth may not be as effective as some natural methods, according to a new paper. The research project applied different types of treatment to identical twins and found that after orthotropics (growth guidance) the facial appearance improved and the teeth stayed straight for longer. Traditional orthodontic methods appeared to cause some damage to the face and the teeth were more likely to re-crowd afterwards.

The study was conducted on a series of twelve identical twins, ten years after treatment. Facial changes were assessed by a panel of ten lay judges. A comparison was also made of the dental changes and an error study undertaken. Most of the traditionally treated twins were judged to look less attractive after treatment while most treated by orthotropics were judged to have improved. There was little difference in the dental results but the traditionally treated cases seemed to relapse to a greater extent after treatment.

Professor John Mew, director of the London School of Facial Orthotropics explained, 'Orthodontic treatment is usually delayed until after growth has stopped by when it may be too late to avoid extractions and 'train tracks'. This research suggests that extractions may be avoided if the growth of the jaws can be corrected, preferably before the age of eight'. The paper appears in the current issue of World Journal of Orthodontics. (Reference was unavailable at time of press. www.quintpub.com)

\section{First anniversary for complaint service}

The Dental Complaints Service, which helps resolve complaints about private dental care, has logged more than 1,500 complaints in its first year of operation. By 15 May - a year since it opened its doors to complaints about any aspect of private dental care - the service had logged and closed 1,559 complaints, many within days.

The service received more than 5,000 enquiries on its local rate complaints hotline (08456 120 540) over the year. Half of these 5,000-plus enquiries were about NHS dental services; these were redirected to the appropriate NHS contact. One in six callers contacted the service at the suggestion of a dental professional.

The policy of the service is to help resolve complaints fairly, efficiently and transparently and it has also had a positive response from dental professionals, who have themselves called the service for advice. Resolving complaints may involve recommending an apology to the patient, a refund of fees and/or a contribution by a dental practice towards the costs of remedial treatment. It may also involve helping the patient to understand that his or her complaint is unjustified. The service was set up by, but is independent of the General Dental Council. 